\title{
NEW TECHNOLOGIES APPLIED TO THE DOCUMENTATION AND ANALYSIS OF EARTHEN ARCHITECTURE: THE SPECIFIC CASE OF THE TARTESSIAN BUILDINGS OF THE CENTRAL GUADIANA VALLEY (SPAIN)
}

\author{
E. Rodríguez González ${ }^{1, *}$, S. Celestino Pérez ${ }^{1}$, C. Lapuente Martín ${ }^{1}$ \\ ${ }^{1}$ Instituto de Arqueología (CSIC - Junta de Extremadura), \\ Mérida, España - (esther.rodriguez, scelestino, carlotalapuente)@iam.csic.es
}

Commission II - WG II/8

KEY WORDS: Tartessos, Guadiana, Landscape Archaeology, Architectural Analysis, Spatial Archaeology, Construction with Earth

\begin{abstract}
:
Until now, the analysis of earthen architecture, characteristic of the Tartessian culture, has been overlooked by archaeological studies. With the aim of incorporating it into historical research as another social product, the result of the society that thinks and builds it, a research project was initiated with the title "Building Tartessos: constructive, spatial and territorial ana lysis of an architectural model in the central Guadiana valley." This project has three well-differentiated work phases whose development and applied methodology are described in the following pages. The purpose of this method is to identify the types of construction, to characterize the raw materials used and their catchment areas, the construction techniques employed, the types of analysis carried out for the mineralogical characterization of the materials, and to present the 3D technology applied to the documentation and registration of the buildings, from photogrammetry to the virtual reconstruction of the archaeological sites. The final objective is to streamline the process, the data collection and the documentation obtained from all of them, from both a purely scientific and informative perspective, improving the publication of scientific knowledge and education through the application of new methodologies. In order to carry out this process, the Tartessian buildings hidden beneath burial mounds characteristic of the central basin of the Guadiana, dating from the 5th century BC, have been selected. Specifically, we have the excavations being carried out in the area of Casas del Turunuelo (Guareña, Badajoz), which to date is the best preserved building in the western area of the Mediterranean, and which will undoubtedly lead to a positive result from the project. The aim of the methodology that has been designed is that it can be applied to any architectural model and to any stage of history.
\end{abstract}

\section{INTRODUCTION}

Defining Tartessos is still a complex task. In spite of this, it is safe to consider it as a result of the hybridization between the local population and the eastern colonizers who arrived on the coasts of the south of the Iberian Peninsula in the 9th century BC (Celestino, López Ruiz, 2016). The mixture between both substrates resulted in a culture with a strong personality, which varied in each of the territories where it prospered, due to the different local roots which were part of this cultural process.

Although Tartessos has traditionally been considered a culture whose territorial centre was located in the valley of the Guadalquivir and Huelva, recent research allows us to extend this territory to the valley of the Guadiana, where the best preserved archaeological remains of this culture are undoubtedly located (Rodríguez González, 2018). The crisis that affected the centre of Tartessos in the 6th century B.C., the causes of which are still unknown, resulted in the expansion of other peripheral territories, such as the Central Guadiana Valley. In this area, between the end of the 7 th century and early 6th century BC a characteristic territorial system was established, dominated by the so-called Tartessian buildings concealed beneath tumuli (Rodríguez González, 2018b).

\section{TARTESSOS}

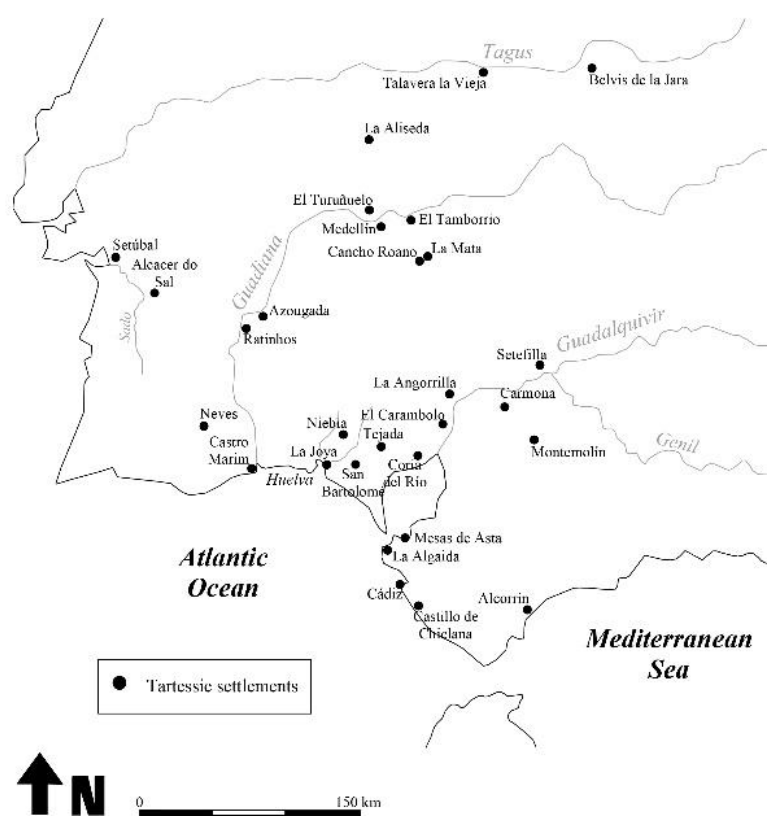

Figure 1. Map of Tartessos.

\footnotetext{
* Corresponding author
} 
These are large buildings with a four-sided floor plan, which are built in an oriental pattern both in terms of their structure and their orientation, which is always towards the east. It has stone foundations that supported adobe walls. After being repaired and abandoned, much of this adobes walls were covered with earth creating some kind of artificial mound that made them unnoticed in the landscape. The chronology of these constructions extends from the beginning of the 6th century $\mathrm{BC}$ to the end of the 5 th century BC, at which time they all suffered a traumatic abandonment preceded by a major fire that put an end to the Tartessian phase of the lands of the interior.

To date, 13 of these buildings beneath the tumulus have been located, but only two of them have been excavated to any extent: these are Cancho Roano (Zalamea de la Serena, Badajoz) (Celestino, 2001, with bibliography) and La Mata (Campanario, Badajoz) (Rodríguez Díaz (ed.), 2004); while a third, the site of Casas del Turuñuelo (Guareña, Badajoz), is currently being excavated and studied. These examples are in addition to interesting sites located in the Guadalquivir valley and the Atlantic coast of Portugal with which they share many cultural similarities, such as El Carambolo (Camas, Seville), Coria del Río (Seville) or Abul (Setubal, Portugal) (Celestino, Rodríguez González, 2016).

Until a few years ago, interest in these enclaves was focused on the study and analysis of the materials they contain, which is why our knowledge of Tartessos remained biased, based exclusively on its reflection within ancient sources and the study of its material culture. The importance of objects such as the treasures of Carambolo (Seville) or Aliseda (Cáceres), as well as the sumptuous ceramic tableware, metalwork or pieces of ivory, eclipsed other aspects of this culture. Architecture is one of the aspects whose characterization has gone practically unnoticed within archaeological and historical studies, barely defined by the similarities between Tartessian buildings and those located in the eastern Mediterranean.

The start of excavation work at the Casas del Turuñuelo site in 2014 marked a turning point in the development of research into Tartessos in the interior of the peninsula. The documentation of a well-conserved building constructed in land, which still preserves two floors, led us to propose a new working methodology for analysing Tartessos; a method based around its architecture understood as a social product, as a cultural expression of the society that thinks and executes it. This new line has been included in the Research Project: Building Tartessos: constructive, spatial and territorial analysis of an architectural model in the Central Guadiana Valley, whose main objective is the study of earthen architecture, characteristic of the Tartessian culture, in order to be able to define patterns, traditions and techniques, with the ultimate aim of determining which construction elements were inherited from the East, those that originated in the local tradition and, finally, those that resulted from the connection between local and external elements, in this case from the Eastern Mediterranean.

As a case study, we selected the aforementioned Tartessian buildings hidden under tumuli, characteristic of the settlement system that prevailed in the Central Guadiana Valley during the First Iron Age, for two fundamental reasons: firstly, they are sites that are in the process of being excavated or have been excavated in their entirety, and secondly, their state of preservation is exceptional if we compare it with the rest of the documented buildings in the southwest of the peninsula. For these reasons it is logical to assume that the volume of information that the buildings inside them contain is much greater.
To carry out this research work, the traditional architectural analysis that includes the study of construction techniques and materials used for this purpose is now joined by the application of new technologies that will allow us to improve the quality of the data acquired, increasing the amount of information derived from the study of the constructions. This is something that is essential within a destructive discipline such as archaeology, where field work is often irreversible, which, as we will see later on, is why it is essential to multiply the number of documentation methods used. Finally, in order to approach this process from the research team, we have designed a working protocol that we present below with the aim of applying it and progressively correcting it, so that it can become a basic methodological model that can be applied to the social study of the constructions from the past.

As a result, for the first time, the Building Tartessos research project integrates purely archaeological study and architectural analysis, a combination that already has antecedents within the study of other protohistoric cultures from the peninsula, such as the Iberian culture (Pastor, 2017), where the analysis of its architecture has a strong historiographic tradition and solid bibliographic support, to which we now also want to add the example of Tartessos.

\section{BUILDING TARTESSSOS}

The Building Tartessos research project was created in 2015 with the aim of incorporating architecture into the archaeological analysis of Tartessos, as a further tool to address its historical knowledge, to overcome the image we had of this culture until just a few years ago.

The project involves, on the one hand, a multidisciplinary team that brings together researchers from various disciplines and specialties, from archaeology, architecture, geology, engineering and chemistry, a structure without which carrying out a project of this nature would be virtually impossible.

On the other hand, a working strategy has been designed in which three complementary phases are integrated: constructive analysis (analytical phase), spatial analysis (comparative phase) and territorial analysis (interpretative phase). Within each of these, various methods and new working technologies applied to the study of earthen architecture, the resources used in the manufacture of building materials and the environments in which these constructions are located are incorporated. The purpose of these analyses is to prepare construction patterns that make it possible to compare the different buildings, with a methodology that can be adapted to any historical stage and geographical region.

\subsection{Constructive analysis, or analytical phase:}

This first phase encompasses the architectural analysis of the different buildings and begins with the study of the walls. This process allows us to record the connections between the different architectural elements, using the methodology of the Archaeology of Architecture (Pizzo, 2009), and to individualise the construction techniques and materials used, the finish of the buildings, the measurement patterns used, the construction solutions and, whenever possible, the accompanying furnishings. Individualising the construction techniques will allow us to determine which are common to Tartessian sites, and which others constitute a novelty within the architectural design. 
In this sense, it is interesting to note how the good state of conservation of the site of Casas del Turuñuelo (Guareña, Badajoz) has allowed us to document construction techniques and building materials unknown until now in prehistoric and protohistoric times in the Iberian Peninsula, as the appearance of some of them was attributed to the Roman domination of Iberia.

The archaeological analysis is fundamental within this phase of work, which includes the excavation of the building under study. Archaeology is a destructive science, everything excavated cannot be returned to its original state. For this reason, graphic documentation of the field work and the results obtained from the excavation is fundamental in order to ensure a correct historical interpretation. In the specific case of the study and excavation of a building made of earth, the difficulty of the archaeological work is further complicated as the building is filled with the same material with which it is constructed, earth and clay. This means we cannot use non-destructive analysis systems such as geophysics or geomagnetism as guides when determining the areas under study, because they are unable to differentiate the constructive elements from the filling material, since they are materials of the same type and conductivity.

The information extracted from the stratigraphic sequence, where the information from the archaeological record is combined both horizontally (sedimentary stratigraphic sequence) and vertically (construction sequence or wall reading), is documented by photogrammetry, a tool that allows us to obtain a high quality image from a combination of a large number of photograms, which later allows us to work at a high level of detail, take measurements, document textures, or design archaeological drawings.
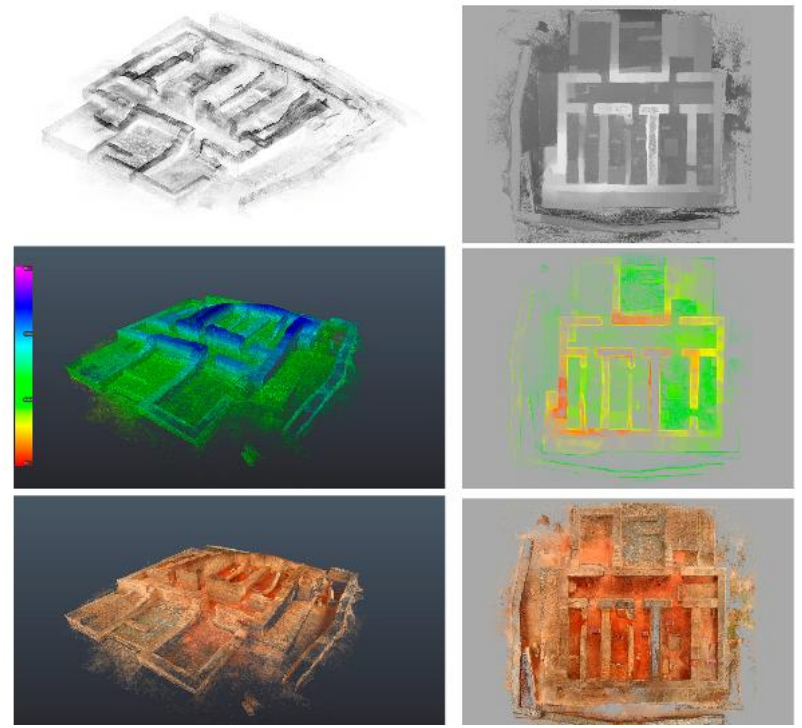

Figure 3. Image of the digital processing of the Tartessian building of La Mata (Campanario). The level of detail achieved in the data acquisition process means it is possible to make measurements and metrological studies, as well as to analyse the presence of construction techniques that are imperceptible in field analysis.

To achieve a greater degree of detail, in addition to the planimetric documentation, all spaces and structures are scanned in 3-D using a phase-shift laser scanner that provides us with a cloud of high-density points that gives us valuable information about the size of the individual elements, absolute distances and locations of an element or relative distances between several, visualisation of the work, colour information associated with different elements, etc.

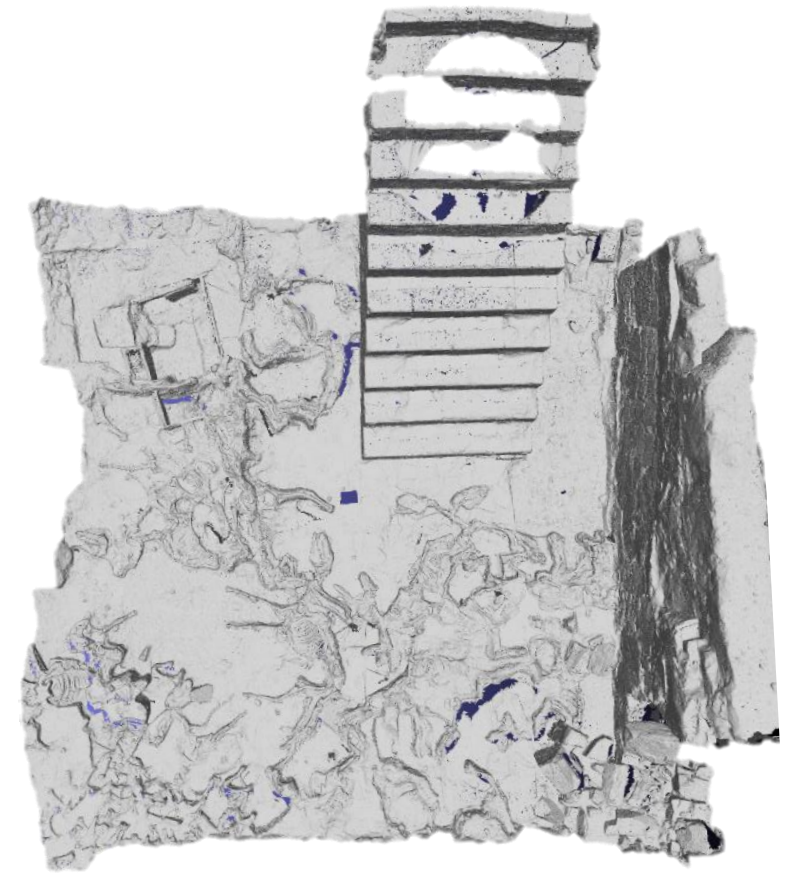

Figure 4. Image of the 3-D scan of a fragment of the courtyard of the Casas del Turunuelo site (Guareña, Badajoz) where it was possible to document part of the northern wall, the staircase, and the animal sacrifice documented on the ground.

The use of this new technology in the study of heritage elements is relatively recent; however, it is very useful, as it makes it possible to obtain a real image of the areas to be excavated and of the spaces once they have been excavated, as well as to integrate the new excavation areas as the field work progresses. One of the most valued uses of this new documentation methodology is its ability to restore objects or complete architectures based on mathematical calculation, allowing fragments or pieces to be returned to their original position with great precision (Pérez Hernández et al., 2012).

All of the graphic documentation work is complemented by the archaeological analysis of the construction materials used, which is fundamental in determining the mineralogical characterization of the raw materials used in the production of adobes, bricks, mortars and plasters. The analytical protocol for each sample includes its macroscopic characterization, the taking of microphotographs, X-ray diffraction and X-ray fluorescence, in addition to new analytical methods that are applied depending on the nature of the sample, as is the case with the Scanning Electronic Microscope for the definition of microstructures, or FT-IR and MicroRam technologies for studying pigments.

The destructive nature of many of these analyses has made it necessary to establish a method of working intended to examine mortars and plasters, as well as clays and adobes, without taking a sample from them, directly on the site itself, something that undoubtedly favours the state of conservation of the site. This is done by means of non-intrusive, high-resolution macroscopy and chromatographic analysis, the data from which is subsequently analysed by means of spectroscopy and colourimetry. These tools even make it possible to obtain a 3-D perspective of the samples, together with quantitative results such as granulometries or spectral, gradient, thermal or infrared images. 
Another innovation incorporated in the study of earth buildings is the use of microstratigraphy or the study of sediments through geoarchaeology, defined as the application of methods and techniques of the earth sciences in the study of the archaeological record, and the investigation of soils and sediments formed in the past. The methodology used is based on the petrographic analysis of thin layers of archaeological soils and sediments, to help us understand the surfaces of occupation of the site and the waste produced by the different activities of cleaning and maintaining these spaces.

\subsection{Spatial analysis or comparative phase}

Building Tartessos includes for the first time within the archaeological discipline the use of Spatial Archaeology to understand the architectural and social facets of the buildings. This is done by analysing the ability of an individual to move through the building, and how the spaces created by the architecture condition the functional qualities of the building. To do so, a syntactic analysis of space is applied, integrating circulation analysis, spatial segregation analysis and visibility analysis. In this way, we will be able to evaluate the degree of intentionality of the location of certain secondary architectural elements, such as pillars, benches or altars, elements which together with the location of the archaeological objects, condition the functionality of the space.

- Gamma analysis: this study consists of the creation of accessibility graphics, which are aimed at identifying the spatial configuration of the interior of the building, how it connects with the exterior, and the schematic projection of the levels of privacy. The analysis of the internal segmentation of a building involves a detailed study of the thresholds, a graphic design of the permeability levels of its different rooms, and a system for measuring spatial relationships through weighted measures, called a numerical value index (Bermejo, 2009).

- Circulation analysis: this consists of the study and the graphic presentation of how the architecture enables or restricts a person's movement through the different rooms of a building. Circulation is the nexus between the spaces, whose purpose is to allow interrelation, as well as the mobility and flow of people and materials. This is a very important point, since the configuration of a route influences the organisational scheme of the spaces it connects. By doing this we can identify the perceptive thread of walking, as well as its direction and purpose. The phases that make up this study are: how to approach the building, the access mode, the configuration of the internal route, and the shape of the spatial route (Mañana et al., 2002).

- Visibility analysis: This section aims to identify the visual domain in a built space and its graphic expression. This study provides information on the degree of privacy of the various rooms, as well as the typification of the order and perceptive organization of the built space and the other elements it contains. This analysis consists of three parts: a study of the visual domain, considering the viewing subject both in a static and in a moving state, in relation to the possible circulation routes established at the precious level; the visibility and visualisation of the materials associated with the rooms, in order to distinguish the elements that are positioned with the intention of being viewed, those that are partially visible and those that are hidden; and the relationship of degrees of privacy by carrying out cumulative visibility analysis.

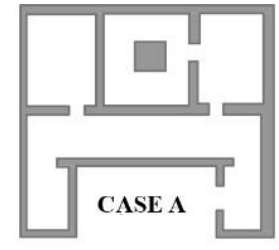

I. PLANIMETRY
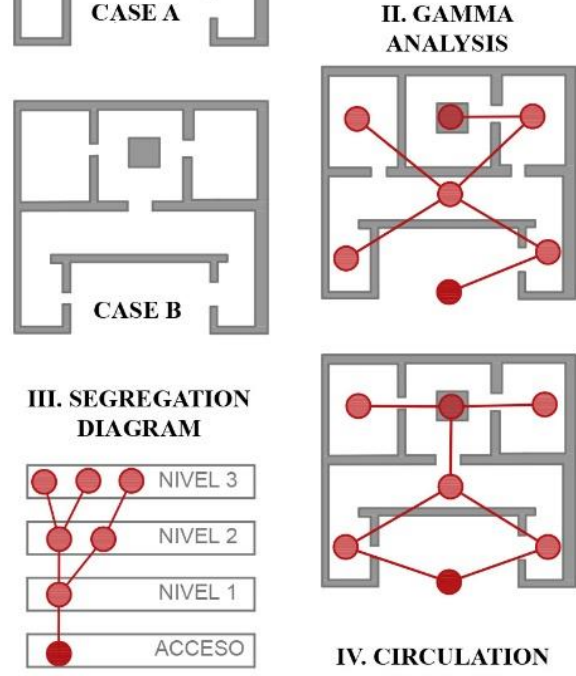

IV. CIRCULATION ANALYSIS
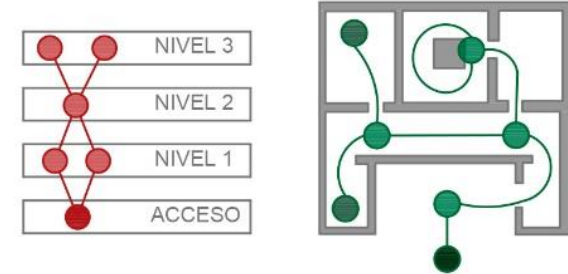

\section{VISIBILITY POINTS}
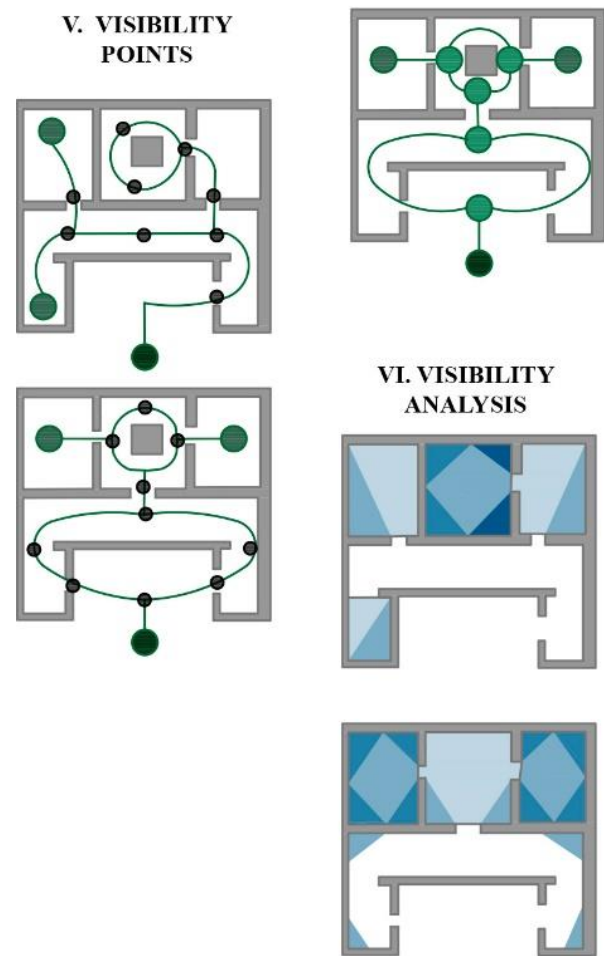

Figure 5. Comparative diagram in which two floors with a very similar formal appearance are presented. From an architectural view they would be interpreted in the same way, given their dimensions and their square floor plan; however, in producing its spatial analysis, it is possible to see the different results that

highlight the importance of this type of analysis in the architectural studies of historical buildings. 
The results obtained in the previous architectural analyses will serve as a starting point for a systematic search for similarities or deviations between the different buildings analysed, as well as the presence or absence of particular elements that have been extracted from the results of the previous analytical phase.

This comparative route branches off into two large hierarchical geographical groups: the regional level, and the general level. In the first, a comparison is made between sites at a local or regional level, in which the connections or divergent elements of the analytical results are compared, generating constructive and organisational typologies. On a second level of comparison, the typological system created at a more global level of all the Tartessian buildings studied is compared in order to determine the degrees of influence and the areas from where these influences originate. This makes it possible to create not only constructive and functional typologies, but also the genealogy of the constructive and organisational characteristics of the buildings included in the study. Therefore, a map of architectural clusters or building groups is created in which we can detect the chronological and spatial evolution of the different components that generate and are generated by the architecture.

\subsection{Territorial analysis, or interpretive phase:}

In carrying out both detailed morphological and paleoenvironmental analysis by using interdisciplinary methods and techniques, we approach the study of the societies that inhabited, anthropized, and built the territory. In this sense, one of the most significant material expressions of a society is its architecture. This architecture is conditioned by the territory in which it is located, the reason why we consider that a first level of analysis is necessarily focused on the study of the physical environment. In this way, an analysis of the areas where resources are obtained will allow us to determine how the individual adapts to the environment and to the resources they have at their disposal in order to design and complete the architectural work (Celestino et al., 2018).

This type of study makes it possible to analyze the reason for the particular location of settlements, and opens the way to studying the relationship between the physical element (the territory) and the social element, and how both are related to each other (the landscape). As a result, we perceive the landscape as the space of interconnection between the natural element and the anthropic element, in which their contacts and forms of relationship take physical shape. Geographic Information Systems are the main tool of this set of analyses, the most important of which are: accessibility analyses to quantify the degree of permeability in a deposit from its different angles; analysis of optimal routes that allow us to determine the most favourable routes for transit between deposits or between these and the areas where raw materials are extracted; analysis of catchment areas, to define natural road links and to identify hypothetical routes for the extraction of resources; or visibility analyses, to study the sensory accessibility of natural and anthropic items at different degrees of distance, topography and atmospheric conditions, as well as the study of relationships of intervisibility.

\section{THE SITE OF CASAS DEL TURUÑUELO AS A STUDY CASE}

The site of Casas del Turuñuelo (Guareña, Badajoz), is located in the area of Vegas Altas del Guadiana, precisely at the point where the River Guadiana joints the rivers Búrdalo and Guadamez, giving it an outstanding position in the landscape.
Although only $20 \%$ of the total area covered by the tumulus that conceals the building has been excavated, the remains recovered to date allow us to consider it as the best case study to individually identify the construction systems and architectural techniques used during the First Iron Age in the southwest of the Iberian Peninsula, as it is the only model from the western Mediterranean that still has its two floors intact, at a height of up to 5 metres.

The excellent state of preservation of the building makes it an exceptional laboratory to study materials and techniques whose appearance in the Iberian Peninsula was previously attributed to the arrival of the Romans. The construction materials that have been recovered so far include several ashlars made from lime mortar, which is the oldest documented man-made mortar in the Iberian Peninsula. These mortar ashlars were used to build the six lower steps of the monumental staircase connecting the two floors of the building (Celestino, Rodríguez González, 2019).

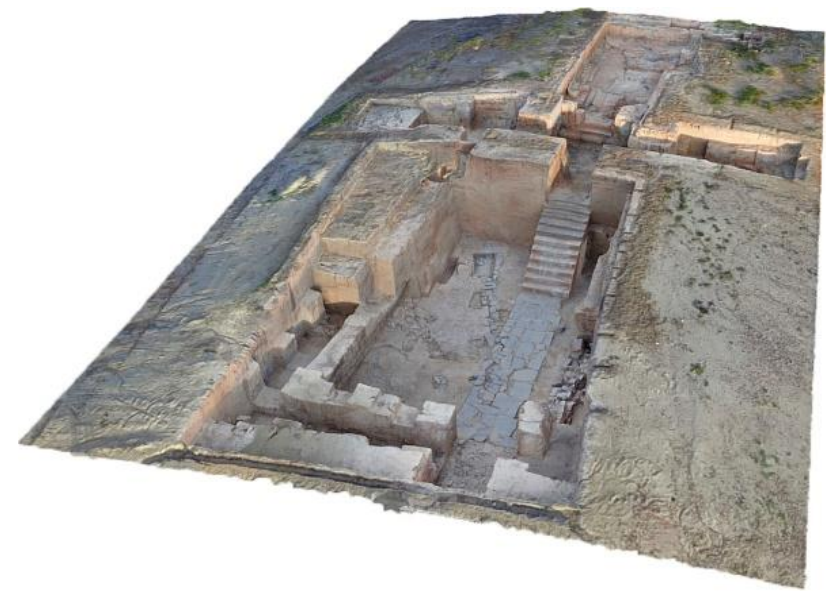

Figure 6. Photogrammetric reconstruction of the site of Casas del Turuñuelo (Guareña, Badajoz) on completion of work on the third campaign of archaeological excavations.

The staircase in the courtyard of Turuñuelo is also a unique example of protohistoric peninsular architecture, due both for the quality of its workmanship and for its outstanding dimensions, as it stands almost 3 metres high. Next to the staircase, another of the construction techniques that stand out on this site is the presence of a Nubian-type brick vault which serves as a roof to cover room 100 or the main room of the building, measuring 60 m2 (Rodríguez González, Celestino, 2017).

This is the first brick vault documented in the Iberian Peninsula from such an early date, a finding that has encouraged us to undertake the search for architectural structures of this type from similar chronologies that are not in such a good state of preservation.

It is at this point in the project that $3-\mathrm{D}$ reconstruction comes into play as a working tool and new technology applied to the study of archaeology and architecture. By processing the data from the study of the site, such as orthographies, planimetry, cross-sections and photogrammetry models, it is possible to create a full-scale architectural model with the necessary precision in each phase of the study, from simple volumetrics to define spaces and architectural structures, through to the detailed lighting of specific scenes that took place during the life of the building. 
However, the 3-D reconstruction of the architecture of a building has a double purpose, as in addition to the exclusively scientific objective, it has an informative capacity, helping to explain it and the different lines of research to the general public, something that was unheard of until a few years ago. Therefore, the divulgation of heritage, both material and built, is the final stop in our methodological model, as we believe that the society that lives alongside the archaeological sites should be the first to support their protection and conservation, to ensure they persist in our memory and within the cultural heritage of our contemporary societies.

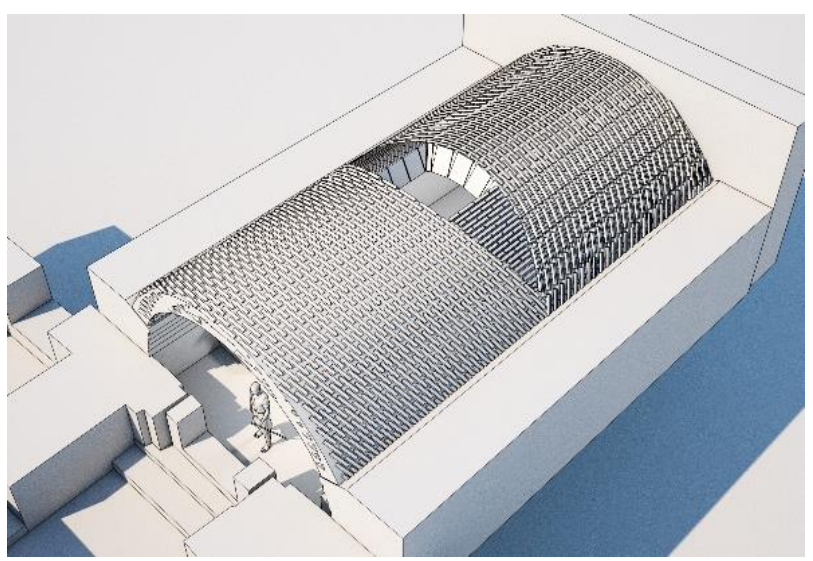

Figure 7. 3-D reconstruction of the vault of room 100 of the Casas del Turuñuelo site (Guareña, Badajoz).

\section{CONCLUSIONS}

The aim of the methodological scheme described in the previous pages is to generate a single model that precludes the application of tools independently and without any connection, a model that has been used up until now, in which connecting archaeology and architecture was a hard work. It is therefore necessary to divide up the component parts of a building: its origin, its construction, and its purpose, not only to understand it but also to comprehend it.

Building Tartessos has opened up a new line of work to help understand the earthen architecture that is typical of Tartessian culture: a line that this project explores for the first time, as to date no working teams had focused on the importance that architecture has as a representative of a social model of thought. In this sense, the very nature of Tartessian culture, a result of the combination of local populations and groups from the Eastern Mediterranean, enriches the objectives of the study, due to the interest in identifying which materials or techniques were legacies of a peninsular tradition, and which were adopted and adapted from other Mediterranean cultures. In this respect, the analysis of each of the structures identified will allow us to distinguish construction models for each of the geographical areas that comprise the Tartessian territory, including with other parts of the Mediterranean and with other cultures that subsequently appeared in the peninsula.

Furthermore, this project addresses for the first time the relationship between the environment and architecture. We conceive the environment as crucial for the development of structures since these depend to a great extent on the place where they are located and on the resources available in their surroundings. In this way, the connection between the paleoenvironment and the architecture will help us to determine the intentionality behind the location of the buildings.

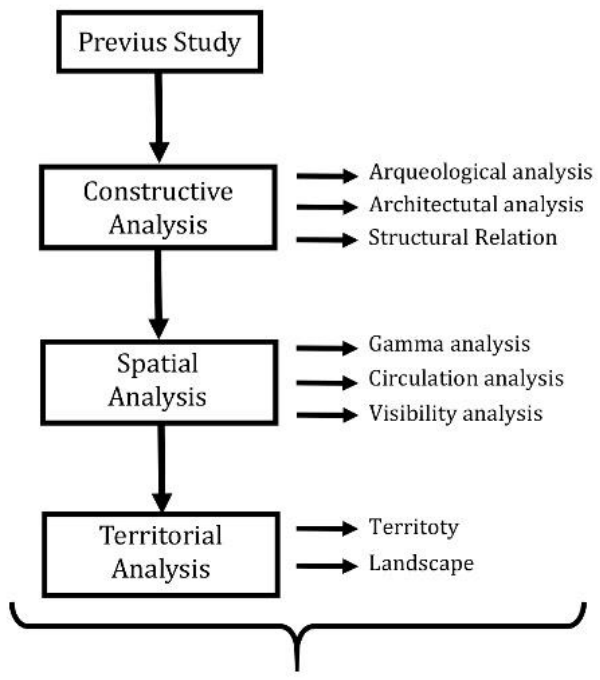

3D - Reconstruction

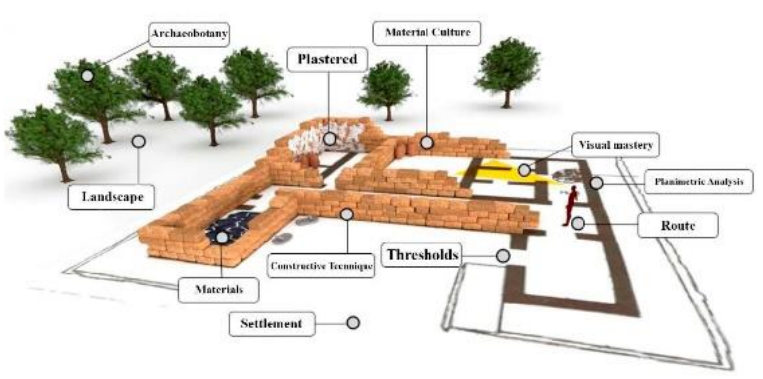

Figure 8. Flow diagram of work on the Building Tartessos project: a constructive, spatial, and territorial analysis of an architectural model in the central Guadiana Valley.

But without a doubt, the greatest strength of this project lies in its innovative methodology and the application of new technologies for the study of architecture and its subsequent historical translation. The adoption of tools from other sciences that are will not only be practical for the study and understanding of Tartessian culture, but their application will be perfectly compatible with any stage of history, making the model presented here all the more versatile.

\section{REFERENCES}

Bermejo, J., 2009. Leyendo los espacios: una aproximación crítica a la sintaxis espacial como herramienta de análisis arqueológico. Arqueología de la Arquitectura, 6, 47-62.

Celestino, S., 2001. Los santuarios de Cancho Roano. Del indigenismo al Orientalismo Arquitectónico, Arquitectura Oriental y Orientalizante en la Península Ibérica, 17-56.

Celestino, S., López-Ruiz, C., 2016. Tartessos and the Phoenicians in Iberia. Oxford University Press, Oxford.

Celestino, S., Rodríguez González, E., 2016. Il riflesso dell'architecttura fenicia in Tartesso. Santuari Mediterranei tra Oriente y Occidente. Interazioni e contatti culturali, 321-328. Scienze \& Lettere, Roma.

Celestino, S., Rodríguez González, 2019. Un espacio para el sacrificio: el patio del yacimiento tartésico de Casas del Turuñuelo (Guareña, Badajoz). Complutum, 30(2), 343-366. doi.org/10.5209/cmpl.66337. 
Celestino, S., Rodríguez González, E., Bashore, C., Dorado, A., Lapuente, C., 2018. La arquitectura como actividad productiva: tres casos de estudio de época tartésica en el valle medio del Guadiana. Trabajo Sagrado. Producción y representación en el Mediterráneo Occidental durante el I Mileno a.C., SPAL Monografías, XXV, 231-249. Universidad de Sevilla, Sevilla.

Mañana, P., Blanco, R., Ayán, X., 2002. Arqueotectura 1: bases teórico-metodológicas para una arqueología de la Arquitectura. Traballos de Arqueoloxía e Patrimonio (TAPA), 2, Santiago de Compostela.

Pastor, M., 2017. La construcción con tierra en arqueología. Teoría, método, técnicas y aplicación. Servicio de Publicaciones de la Universidad de Alicante, Alicante.

Pérez Hernández, E., Salamanca, S., Cerrada, C., Merchán, P., Adán, A., 2012. "Relleno de huecos en mallas 3D completas mediante algoritmos de restauración de imagen", Revista Iberoamericana de Automática e Informática industrial, 9, 429440. doi. org/10.1016/j.riai.2012.09.010.

Pizzo, A., 2009. La Arqueología de la Construcción. Un laboratorio para el análisis de la arquitectura de época romana. Arqueología de la Arquitectura, 6, 31-45.

Rodríguez Díaz, A. (ed.), 2004. El Edificio Protohistórico de la Mata (Campanario, Badajoz) y su estudio territorial. Universidad de Extremadura, Cáceres.

Rodríguez González, E., 2018. El poblamiento del valle medio del Guadiana durante la I Edad del Hierro. Biblioteca Praehistorica Hispana, XXXIV. CSIC, Madrid.

Rodríguez González, E., 2018b. The Tartessian Tumuli of the Guadiana. Rivista di Studi Fenici, 46, 117-136.

Rodríguez González, E., Celestino, S., 2017. Las estancias de los dioses: la habitación 100 del yacimiento de Casas del Turuñuelo (Guareña, Badajoz). Cuadernos de Prehistoria y Arqueología de la Universidad Autónoma de Madrid, 43, 179-194. doi.org/10.15366/cupauam2017.43.006 